\title{
Evaluation of the Rapid Weight Loss Practices of Taekwondo Athletes and Their Effects
}

\author{
Sinan Seyhan \\ Correspondence: Sinan Seyhan, Faculty of Sport Sciences, Celal Bayar University, Manisa, Turkey.
}

Received: August 3, 2018

doi:10.11114/jets.v6i10.3663

Accepted: September 25, 2018

Online Published: September 28, 2018

URL: https://doi.org/10.11114/jets.v6i10.3663

\begin{abstract}
This study was conducted to determine the physiological and psychological effects of the weight loss by determining the weight loss methods commonly used by taekwondo athletes. Of the questionnaires evaluated, 107 belonged to female taekwondo athletes and 195 belonged to male taekwondo athletes. The arithmetic average, standard deviation and percent frequency (\%) distributions of the obtained data were calculated. It was determined that the; first weight loss age for the competition is $15,66 \pm 3,84(\mathrm{~kg})$ in males and $15,95 \pm 3,16(\mathrm{~kg})$ in females; the highest weight loss rate before the competition is $4,52 \pm 2,77(\mathrm{~kg})$ in males and 4,40 $\pm 5,36(\mathrm{~kg})$ in females. It was stated that $30.3 \%$ of male athletes and $41.1 \%$ of female athletes start to lose weight 3-4 weeks before the competition, that male and female athletes prefer the diet method most frequently as a rapid weight loss method and $21.5 \%$ of athletes who use the weight loss method with fluid loss prefer to run with raincoat. The athletes do not use ergogenic aids and the frequency percentage of physiological (muscle cramps, body temperature increase, heart throb, dyspnea, injury) and psychological (excessive nervousness, low performance due to high fatigue, stress) adverse effects of fast weight loss is very low.
\end{abstract}

Conclusion: Unlike other martial athletes, it has been determined that Taekwondo athletes do not start to lose weight at an early age and that the majority of them try to reach the weight they want by applying the diet method among rapid weight loss methods in a very short time before the competition.

Keywords: weight loss methods, taekwondo, diet

\section{Introduction}

Physical appearance, body mass, shape and size of the body are very important for high performance in many sports branches. Athletes who have this awareness know that they need to routinely monitor their body composition throughout the season (Slater, O'Connor, Kerr, 2017). Unlike other combat sports, martial sports are typically sports branches in which the athletes are divided into categories according to their body weights and compete against the opponents of the same weight category. Previous studies showed that martial athletes apply more weight loss methods than other combat sports (Barley, Chapman, Abbiss, 2017). Different applications for reducing the body weights that athletes usually use before they compete in these sports branches with the weight categories are a widely used approach in order to perform better in a lower weight category. Thus, athletes try to achieve physical and mental advantages against other competitors by rapidly reducing their body weight (Gann, Grant, La Bounty, 2015). Most athletes competing in the weight category sports lose weight for tactical purposes due to reasons such as having a body weight between two categories, or because the athletes competing in a subcategory may be less strong, fast and enduring, or there may be better competitors in their own category (Yarar, Eroglu, Uzum, Polat, 2016). It is known that weight category athletes lose more than $5 \%$ of their body weight in less than a week in order to compete in their own weight category, to improve their performance potential, to achieve superiority over a weaker and thinner competitor in a lower weight category, or to appear more aesthetic (Brito et al., 2012; Maughan, R. J., 2000).

It is known that for fast and effective weight loss, athletes with weight problems prior to the competition try to reduce their body weight by using methods such as restriction of food intake, loss of fluid through sweating, limitation of fluid intake, intentional vomiting, use of laxatives and diuretic pills and dehydration by staying in the sauna for a long time. With these methods, the physical, physiological and mental health of the athletes participating in the competition are put at risk (Filaire, Maso, Degoutte, Jouanel and Lac 2001; Bradley, D. D. 2006; Berkovich, Eliakim, Nemet, Stark \& Sinai, 2016). Trying to lose weight through these methods and frequently used fluid loss method can negatively affect the athlete's performance, cardiovascular function, electrolyte activity, internal thermal balance, renal function, and 
electrolyte balance (Fleming, Costarelli, 2009). In addition, despite the different opinions in the literature, it is known that precompetition weight loss results in both aerobic and anaerobic performance disorders (increase in heart rate, decrease in oxygen consumption, dehydration, decrease in plasma volume, hydroelectrolytic disorders, thermoregulation disorder and depletion of muscle glycogen storages) (Fogelholm, 1994; Weiss, Racette, Villareal, Karen, 2007). The high performance of athletes involved in the taekwondo branch, which is a sports with weight categories, is closely related to the low body weight of the athletes. For this reason, the athletes who are involved in the taekwondo branch regularly try these applications which include different weight loss methods before competitions (Kazemi, Rahman, De Ciantis, 2011).

Taekwondo athletes using different weight loss methods are adversely affected psychologically at the same time besides adverse physiological effects to which athletes competing in other sports branches are exposed to. Temporary mental disorders such as anger, fatigue and tension may be a result of physiological effects arising from weight regulation, such as dehydration or hypoglycaemia. This situation can cause the athlete to feel mentally worse (Choma, Sforzo, Keller, 1998). It was found out that a total of 87 percent of Taekwondo athletes participating in a questionnaire on weight loss methods in a study applied the methods involving practices aimed at reducing body weight before competition in order to compete in their own weight category, and that 47 percent of the athletes used methods to restrict their intake of fluids and increased energy expenditure to lose weight. 80 percent of the athletes participating in the same study said they tried practices involving methods for reducing body weights from six to nine times a year on average (Fleming, Costarelli, 2009).

It is known that Taekwondo athletes often lose weight before competitions in the active period, suffer physiological and psychological problems due to weight loss, and will also experience them in the long term. This study was conducted in order to reveal the physiological and psychological effects of weight loss by determining the weight loss methods taekwondo athletes usually use in order to compete in the lower weight category.

\section{Method}

This study has been designed with the descriptive survey model among the quantitative research methods. In order to determine the weight loss methods and their effects on the athletes, the sample group consisted of athletes who were actively involved in taekwondo sports, who were not heavyweight athletes and who lost weight before the competition. 302 of the collected questionnaires, which were determined to have been filled in correctly, were evaluated. Of the questionnaires evaluated, 107 belonged to female participants and 195 belonged to male participants.

The expression pool consisting of 32 items and 5 categories, a measurement tool developed by Yarar et al. under the name of "Athlete Weight Loss Methods and Effects Scale" to the athletes who participated in İsmet Iraz Büyükler Turkish Taekwondo Championship organized in Antalya (Yarar et al., 2016).

SPSS 21 program was used for the statistical analysis in this study. The data obtained as a result of the questionnaire applied to participants, participants' descriptive characteristics, weight loss history, arithmetic average (X), standard deviations (SS), percent frequency (\%) distributions were analyzed.

\section{Findings}

The results obtained from 302 taekwondo athletes participating in the study are presented in tables below. The descriptive statistics of Taekwondo athletes participating in the study are shown in Table 1.

Table 1. Descriptive Statistics of Taekwondo Athletes

\begin{tabular}{|c|c|c|}
\hline & Male $(n=195) x+s s$ & Female $(n=107) x+s s$ \\
\hline Age (year) & $21,95 \pm 4,42$ & $21,03 \pm 3,58$ \\
\hline \multicolumn{3}{|l|}{ Education $(\%)$} \\
\hline Primary education & 3,1 & - \\
\hline High school & 38,5 & 43,9 \\
\hline University & 51,3 & 52,3 \\
\hline Postgraduate & 7,2 & 3,7 \\
\hline \multicolumn{3}{|l|}{ National Athlete $(\%)$} \\
\hline Age of starting Taekwondo (years) & $11,75 \pm 3,23$ & $11,22 \pm 3,38$ \\
\hline Age of first weight loss for competition $(\mathrm{kg})$ & $15,66 \pm 3,84$ & $15,95 \pm 3,16$ \\
\hline Maximum weight loss before competition $(\mathrm{kg})$ & $4,52 \pm 2,77$ & $4,40 \pm 5,36$ \\
\hline Number of weight losses in a season $(\mathrm{kg})$ & $2,31 \pm 1,80$ & $1,92 \pm, 97$ \\
\hline
\end{tabular}

The descriptive statistics of the participants are given in Table 1. For the Taekwondo athletes participating in the study, the average values of the age of starting Taekwondo is 11,75 $\pm 3,23$ (years) in males and 11,22 $\pm 3,38$ (years) in females, the average age of the first weight loss for competition is $15,66 \pm 3,84$ (years) in males and 15,95 $\pm 3,16$ (years) in females. It was determined that the highest average weight loss rate average before the competition in which they participated during the season is $4,52 \pm 2,77 \mathrm{~kg}$ in males and $4,40 \pm 5,36 \mathrm{~kg}$ in females, the number of weight losses in a season is $2,31 \pm 1,80$ in males and $1,92 \pm, 97$ in females. 
Table 2. Time of Starting Weight Loss before Competition of Taekwondo Athletes

\begin{tabular}{|c|c|c|c|c|c|}
\hline \multirow{8}{*}{$\begin{array}{l}\text { How many days before the } \\
\text { competition do you start to lose } \\
\text { weight? }\end{array}$} & & $(n=195)$ & Male (\%) & $(n=107)$ & Female $(\%)$ \\
\hline & 1-2 days before & 25 & 12,8 & 12 & 11,2 \\
\hline & 3-4 days before & 13 & 6,7 & 6 & 5,6 \\
\hline & In the last week & 14 & 7,2 & 11 & 10,3 \\
\hline & In the last 2 weeks & 57 & 29,2 & 25 & 23,4 \\
\hline & 3-4 weeks before & 59 & 30,3 & 44 & 41,1 \\
\hline & Other & 27 & 13,8 & 9 & 8,4 \\
\hline & Total & 195 & 100 & 107 & 100 \\
\hline
\end{tabular}

It was found that $30.3 \%$ of the male athletes started to lose weight 3-4 weeks before the competition in which the participant Taekwondo athletes participated and $29.2 \%$ started to lose weight within the last two weeks; on the other hand, $41.1 \%$ of the female athletes started to lose weight in the last two weeks and $23.4 \%$ started to lose weight $3-4$ weeks before the competition. Percentages of male and female athletes who tried to lose weight 1-2 days before the competition were determined as $12.8 \%$ and $11.2 \%$ respectively (Table 2 ).

Table 3. Weight Loss Methods of Taekwondo Athletes

$$
\text { Never (\%) Rarely (\%) } \quad \text { Sometimes (\%) } \quad \text { Often (\%) } \quad \text { Always (\%) }
$$

\begin{tabular}{|c|c|c|c|c|c|}
\hline \multicolumn{6}{|l|}{$\operatorname{Diet}(\%)$} \\
\hline I reduce food consumption & 14,2 & 14,2 & 16,6 & 24,5 & 30,5 \\
\hline I reduce carbohydrate consumption & 5,6 & 21,9 & 17,2 & 25,8 & 29,5 \\
\hline I reduce fat consumption & 3,6 & 16,6 & 19,5 & 28,1 & 32,1 \\
\hline \multicolumn{6}{|l|}{ Liquid $(\%)$} \\
\hline I run with a raincoat & 11,6 & 27,5 & 23,2 & 16,2 & 21,5 \\
\hline I stay in the sauna & 31,5 & 27,2 & 23,8 & 11,3 & 6,3 \\
\hline I lose weight by spitting & 71,5 & 9,3 & 7,3 & 7,3 & 4,6 \\
\hline \multicolumn{6}{|l|}{ Ergogenic (\%) } \\
\hline I use laxative pills & 57,0 & 18,9 & 12,3 & 7,3 & 4,6 \\
\hline I use diet pills & 63,6 & 13,9 & 9,9 & 7,6 & 5,0 \\
\hline I use diuretic pills & 63,6 & 13,2 & 11,3 & 3,6 & 8,3 \\
\hline
\end{tabular}

When the weight loss methods applied by Taekwondo athletes are examined, it was stated that the percentage of athletes targeting weight loss using the diet method is high and the most commonly used method is to reduce fat consumption with the percentage of $32.1 \%$. It is understood that $21.5 \%$ of the athletes who use weight loss method with liquid loss prefer running with raincoat. It was also found that taekwondo athletes participating in the study did not use unnatural methods (laxative 57\%, diet and diuretic pills 63.6\%) which cause rapid weight loss.

Table 4. Effects of Weight Loss on Physical, Physiological, Psychological States and Performance in Taekwondo Athletes

\begin{tabular}{|c|c|c|c|c|c|}
\hline & Never $(\%)$ & Rarely (\%) & Sometimes $(\%)$ & Often $(\%)$ & Always (\%) \\
\hline \multicolumn{6}{|l|}{ Physiological (\%) } \\
\hline I experience muscle cramps & 47,7 & 25,2 & 14,6 & 5,6 & 7,0 \\
\hline My body temperature increases & 49,7 & 25,8 & 11,3 & 7,0 & 6,3 \\
\hline I experience heart throb & 53,3 & 26,2 & 9,3 & 7,0 & 4,3 \\
\hline I experience dyspnea & 52,0 & 25,2 & 11,9 & 6,6 & 4,3 \\
\hline I experience injury & 48,7 & 25,5 & 16,2 & 5,6 & 4,0 \\
\hline \multicolumn{6}{|l|}{ Psychological (\%) } \\
\hline I get excessively angry & 21,5 & 34,4 & 21,9 & 15,6 & 6,6 \\
\hline I feel extremely tired & 15,6 & 31,1 & 29,1 & 14,6 & 9,6 \\
\hline My performance drops & 17,2 & 30,1 & 29,5 & 16,6 & 6,6 \\
\hline I experience stress & 17,5 & 24,5 & 27,8 & 19,9 & 10,3 \\
\hline My desire to do sport decreases & 25,5 & 26,8 & 22,8 & 11,9 & 12,9 \\
\hline
\end{tabular}

Table 4 shows the levels of physical, physiological, psychological and performance effects as a result of weight loss methods applied by Taekwondo athletes. It was found that $12.9 \%$ of the respondents who participated in the questionnaire had a reduced willingness to perform this sport after weight loss, $10 \%$ experienced stress after they started to lose weight and afterwards, and $7 \%$ were exposed to muscle cramps. The responses of the athletes to the questionnaire reveal that the percentages of the physiological dimension of the weight loss are low.

\section{Discussion and Conclusion}

This study was applied to the athletes of Taekwondo to examine the rapid weight loss methods used before the competition in order to compete in the desired weight category and to gain physical, psychological and physiological 
advantages against other competitors and the effect of these methods on the athletes. It was determined that the average age of starting this sports branch of taekwondo athletes participating in this study was 11,75 $\pm 3,23$ years and that the age of starting to use weight loss method of the athletes participating in the study was $15,66 \pm 3,84$ years. In the literature, in the study by Artioli et al. (Artioli et al., 2010a) revealed that the first age of starting to use weight loss methods for judo athletes was 12 years. In another study, indicate that the first age of starting to use weight loss methods for taekwondo athletes prefer is $14.2 \pm 2.1$ years. (Brito et al., 2012) Our results and previous studies in the literature show that the age at which taekwondo athletes first start to lose weight is higher than judo athletes. The preference of weight loss methods at the early ages by the athletes, the selection of the wrong methods to lose weight will bring about the poor performance, the physical, physiological and psychological effects that can be caused by the weight loss.

In the study by Fortes et al., they reported that a $10 \%$ reduction in body weight of the taekwondo athletes before the competition had no effect on match performance and did not improve taekwondo skills (Fortes, Vasconcelos, Costa, Paes and Franchini, 2017). In this study, the highest average weight loss rate of taekwondo athletes before the competition during the season is $4.52 \pm 2,77 \mathrm{~kg}$ in males and $4.40 \pm 5.36 \mathrm{~kg}$ in females. These findings are similar to those previously reported by Brito et al. (Brito et al., 2012). Farhan et al., found in their study on the wrestlers that the highest weight loss was $3.06 \mathrm{~kg}$ for the greco-roman wrestling and $3.58 \mathrm{~kg}$ for the free style wrestling. (Farhan, Amirsasan \& Mahdavi, 2014). It was observed that the times when taekwondo athletes participating in the study start to lose weight before the competition were 3-4 weeks before in male athletes (30.3\%) and female athletes $(41.1 \%)$. In our study, it is seen that taekwondo athletes start the first weight loss early before the competition in contrast with the findings of other studies.

When the weight loss methods applied by Taekwondo athletes participating in the study are examined, it is understood that the most commonly used method is the diet method with decreasing consumption of $32.1 \%$ fat, $30.5 \%$ food, $29.5 \%$ carbohydrate and that those who use these methods have a higher percentage than the ones who aim to lose weight by using other methods. Brito et al., indicate the most common rapid weight loss methods used by young taekwondo athletes as low calorie diet (70.5\%), carbohydrate restriction (56.8\%) and fat restriction (47.4\%) respectively (Brito et al., 2012). In a study conducted by Catıkkaş, it was determined that the most preferred rapid weight loss methods by young elite taekwondo athletes were $65.7 \%$ staying hungry, $42.9 \%$ skipping meals, and $28.6 \%$ uniform diet. It is noteworthy that $21.5 \%$ of athletes who use the weight loss method with liquid loss prefer running with a raincoat and the percentage of those who prefer to use the sauna among weight loss methods is low. Catıkkaş, reported that $42.9 \%$ of the young elite taekwondo athletes try to lose weight by using sauna and $60 \%$ wear thick clothes for fluid loss among the weight loss methods (Catıkkas, 2016). In another study, the percentage of those who used the method of fluid loss by using the sauna was 52.6\% (Brito et al., 2012; Barley et al., 2017), who examined the weight loss methods of mixed martial sports athletes, showed that the athletes use the sauna $67 \%$ as the most common method of weight loss. It was found that, of the taekwondo athletes participating in this study, $57 \%$ had never used laxatives, $63.6 \%$ had never used a diet and $63.6 \%$ had never used diuretic drugs. Determined that the percentage of those who used the fluid loss method in young taekwondo athletes is $41.1 \%$ and the percentage of those who used diuretics or laxatives was $42.1 \%$. The use of laxatives and diuretics as fast weight loss methods is defined as unhealthy weight loss practices. (Brito et al., 2012). On the other hand state that the percentage of use of fluid loss methods to lose weight among wrestlers is 2-5\% (Artioli et al., 2010b).

When studies on rapid weight loss in the literature are examined, it is seen that all studies associate the weight loss with the success and there are no studies in which the weight loss is associated with the failure (Artioli, Saunders, Iglesias, R., Franchini, 2017). When psychologically adverse effects of weight loss are evaluated, reported that the negative effects of weight loss were 58.3\% dizziness, $57.3 \%$ susceptibility and irritability, 50.0\% concentration impairment, and $41.7 \%$ headache (Bradley 2006). Some studies suggested that there is a decrease in athlete's performance after a rapid weight loss, and other studies indicated that there is no performance change in the athletes after a rapid weight loss. Horswill et al. found that measurements in both groups before and after losing $6 \%$ of their body weights resulted in increased levels of tension, fatigue, depression and anxiety as well as a decrease in force measurements made in both groups (Horswill, Hickner, Scott, Costill, Gould, 1990). Artioli et al., reported in their study on the judo athletes that participants did not show any change in body composition and performance after 4 hours of rapid weight loss (Artioli et al., 2010a). In another study conducted with eighteen male martial athletes, it was reported that no change in the performance of athletes after weight loss resulted from the recovery period, and food and fluid intake during this period (Mendes et al., 2013). The fact that athletes become mentally ready before important competitions is an important situation for athletes and coaches in order to gain a superiority over other competitors. Pettersson et al., observed in their study that weight loss desire of the athletes before competition increased their desire for competition by providing mental comfort against the opponent, more concentration and a desire to win the competition rather than the physical advantage (Petterson, Ekstrom \& Berg, 2013). 
In this study, in which we examined the physiological dimensions of weight loss in Taekwondo athletes, it is seen that these athletes have a low incidence of physiological disorders such as muscle cramps (7\%), body temperature increase (6.3\%), heart throb (4.3\%), dyspnea (4.3\%) and injury (4\%) after weight loss. In the study by Bradley on the physiological dimensions of weight loss, it was stated that there can be $45.8 \%$ muscle cramps and $33.3 \%$ increase in heart rate in sudden weight loss (Bradley, 2006). Beyleroğlu et al. stated that rapid weight loss may cause heart rate disorders and that starting to lose weight at least 3 months before the competition may be a more correct application in order not to encounter this situation (Beyleroglu, Hazar, Yalcın, Uca, Akkus, 2014). Rashidlamir et al., they have recommended wrestlers to use this gradual weight loss method in order to maintain the physiologic parameters of their body, to lose weight without harmful side effects and to have better performance (Rashidlamir, Goodarzi, Ravasi 2009). Green et al. found in their study that athletes who reduced their body weights by more than $5 \%$ with diet or different methods before competition are very likely to be injured during the competition (Green, Petrou, Fogarty-Hover, Rolf, 2007). In this study, it was stated that the incidence of injuries in Taekwondo athletes who prefer different weight loss methods is very low.

It is noteworthy that taekwondo athletes participating in this study stated that there was no change in their physical, physiological and psychological performance levels during and after the weight loss, even though there are many deficiencies related to rapid weight loss in the literature. In conclusion, it is understood that Taekwondo athletes prefer and apply different weight loss methods for higher performance, without harmful side effects, by preserving the physiological parameters of the body. In addition, all athletes who will participate in the competitions should be provided with appropriate nutrition education and support, and athletes who are considering to apply harmful methods not suitable for their health and performance with the aim of rapid weight loss should be informed about this issue. In this regard, coaches, athletes' families and friends have a great responsibility.

\section{References}

Artioli, G. G., Gualano, B., Franchini, E., Scagliusi, F. B., Takesian, M., Fuchs, M., \& Lancha Jr, A. H. (2010b). Prevalence, magnitude, and methods of rapid weight loss among judo competitors. Med. Sci. Sports Exerc., 42(3), 436-442. https://doi.org/10.1249/MSS.0b013e3181ba8055

Artioli, G. G., Iglesias, R. T., Franchini, E., Gualano, B., Kashiwagura, D. B., Solis, M. Y., ... \& Lancha Jr, A. H. (2010a). Rapid weight loss followed by recovery time does not affect judo-related performance, J. Sports Sci., 28(1), 21-32. https://doi.org/10.1080/02640410903428574

Artioli, G. G., Saunders, B., Iglesias, R. T., \& Franchini, E. (2017). Reply to Davis: It is time to ban rapid weight loss from combat sports, Sports Med., 47, 1677-1681. https://doi.org/10.1007/s40279-017-0715-1

Barley, O. R., Chapman, D. W., \& Abbiss, C. R. (2017). Weight loss strategies in combat sports and concerning habits in mixed martial arts, Int. J. Sports Physiol. Perform., 28. 1-24.

Berkovich, B.E., Eliakim, A., Nemet, D., Stark, A. H. \& Sinai, T. (2016). Rapid weight loss among adolescents participating in competitive judo. Int. J. Sport Nutr. Exerc. Metab., 26(3), 276-284. https://doi.org/10.1123/ijsnem.2015-0196

Beyleroglu, M., Hazar, M., Yalcın, S., Uca, M., \& Akkus, M. (2014). Research of sudden weight loss effects on pulse of boxers, Procedia - Social and Behavioral Sciences, 152, 495-499. https://doi.org/10.1016/j.sbspro.2014.09.239

Bradley, D. D. (2006). Prevalence and Effects Rapid Weight Loss among International style Wrestlers. Dept. HPER, Northern Michigan University, Marquette, MI, USA 1401 Presque Isle Marquetta, 1-17.

Brito, C. J., Roas, A. F., Brito, I. S. S., Marins, J. C. B., Córdova, C., \& Franchini, E. (2012). Methods of body mass reduction by combat sport athletes. Int. J. Sport Nutr. Exerc. Metab., 22(2), 89-97. https://doi.org/10.1123/ijsnem.22.2.89

Catıkkas, F. (2016). Unhealthy weight loss behaviors of young Taekwondo athletes, CBU J. Phys. Edu. Sport Sci., 11(2), 125-130.

Choma, C. W., Sforzo, G. A., \& Keller, B. A. (1998). Impact of rapid weight loss on cognitive function in collegiate wrestlers, Medicine and Science in Sports and Exercise, 30(5), 746-749. https://doi.org/10.1097/00005768-199805000-00016

Farhan, H., Amirsasan, R., \& Mahdavi, B. (2014). The comparison methods and effect of rapid weight loss between elite teen freestyle and Greco-Roman wrestlers. Bull. Env. Pharmacol. Life Sci., 3(2), 441-445.

Filaire, E., Maso, F., Degoutte, F., Jouanel, P., \& Lac, G. (2001). Food restriction, performance, psychological state and lipid values in judo athletes, International Journal of Sports Medicine, 22, 454-459.

https://doi.org/10.1055/s-2001-16244 
Fleming, S., \& Costarelli, V. (2009). Eating behaviours and general practices used by taekwondo players in order to make weight before competition, Nutrition \& Food Science, 39(1), 16-23. https://doi.org/10.1108/00346650910930770

Fogelholm, M. (1994). Effects of bodyweight reduction on sports performance. Sports Med., 18, 249-267. https://doi.org/10.2165/00007256-199418040-00004

Fortes, L. S., Vasconcelos, G. C., Costa, B. D. V., Paes, P. P., \& Franchini, E. (2017). Effect of 10\% weight loss on simulated taekwondo match performance: a randomized trial, J. Exerc. Rehabil., 13(6), 659-665. https://doi.org/10.12965/jer.1735134.567

Gann, J. J., Grant, T. M., \& La Bounty, P. M. (2015). Weight cycling: prevalence, strategies, and effects on combat athletes. Strength Cond. J., 37(5), 105-111. https://doi.org/10.1519/SSC.0000000000000168

Green, C. M, Petrou, M. J., Fogarty-Hover, M. L. S., \& Rolf, C. G. (2007). Injuries among judokas during competition. Scand. J. Med. Sci. Sports., 17, 205-210.

Horswill, C. A, Hickner, R. C, Scott, J. R, Costill, D. L, \& Gould, D. (1990). Weight loss, dietary carbohydrate modifications, and high intensity, physical performance, Med. Sci. Sports Exerc., 22(4), 470-476. https://doi.org/10.1249/00005768-199008000-00009

Kazemi, M., Rahman, A., \& De Ciantis, M. (2011). Weight cycling in adolescent taekwondo athletes, The Journal of the Canadian Chiropractic Association, 55(4), 318-324.

Maughan, R. J. (2000). Nutrition on Sport. Jack H. W1lmore Weight Category Sports Wiley-Blackwell. Chapter 49; 637-644. https://doi.org/10.1002/9780470693766

Mendes, S. H, Tritto, A. C, Guilherme, J. P., Solis, M. Y., Vieira, D. E., Franchini, E., ... \& Artioli, G. G. (2013). Effect of rapid weight loss on performance in combat sport male athletes: does adaptation to chronic weight cycling play a role? Br. J. Sports Med., 47(18), 1155-1160. https://doi.org/10.1136/bjsports-2013-092689

Petterson, S., Ekstrom, M. P., \& Berg, C. M. (2013). Practices of weight regulation among elite athletes in combat sports: a matter of mental advantage? J. Athl. Train., 48(1), 99-108. https://doi.org/10.4085/1062-6050-48.1.04

Rashidlamir, A., Goodarzi, M., \& Ravasi A. (2009). The Comparison of Acute and Gradual Weight Loss Methods in Well-Trained Wrestlers. World Journal of Sport Sciences, 2(4), 236-240.

Slater, G., O’Connor, H., \& Kerr, A. (2017). Optimising Physique for Sports Performance, Best Practice Protocols for Physique Assessment in Sport, 27-36.

Weiss, E. P., Racette, S. B., Villareal, D. T., \& Karen, L. F. (2007). Lower Extremity Muscle Size and Strength and Aerobic Capacity Decrease with Caloric Restriction But not with Exercise-Induced Weight Loss. J. Appl., 102(2), 634-640.

Yarar, H., Eroglu, H., Uzum, H., \& Polat, E. (2016). Athlete Weight Loss Methodology and Effects Scale: Validity and reliability study. 13(3), 6164-6175.

\section{Copyrights}

Copyright for this article is retained by the author(s), with first publication rights granted to the journal.

This is an open-access article distributed under the terms and conditions of the Creative Commons Attribution license which permits unrestricted use, distribution, and reproduction in any medium, provided the original work is properly cited. 